\title{
Correction to: Making urinary extracellular vesicles a clinically tractable source of biomarkers for inherited tubulopathies using a small volume precipitation method: proof of concept
}

\author{
Timothy Lee Williams $^{1}$ D $\cdot$ Carlos Bastos $^{1} \cdot$ Nuno Faria $^{1} \cdot$ Fiona Eve Karet Frank $\left.\right|^{2}$
}

Published online: 5 November 2019

(c) Italian Society of Nephrology 2019

\section{Correction to: Journal of Nephrology \\ https://doi.org/10.1007/s40620-019-00653-8}

The original published article the section Acknowledgements is missing. The section is given below:

\section{Acknowledgements}

The authors would like to acknowledge Caroline Robinson for her assistance with the study and the Academy of Medical Sciences for funding the study.

The original article can be found online at https://doi.org/10.1007/ s40620-019-00653-8.

Timothy Lee Williams

timwilliams@cantab.net

1 Department of Veterinary Medicine, University

of Cambridge, Madingley Road, Cambridge CB3 OES, UK

2 Department of Medical Genetics and Division of Renal Medicine, University of Cambridge and Cambridge

University Hospitals Foundation Trust, Cambridge, UK 